\title{
O homem como uma somatória unitária de Erlebnisse (vivências) em Nietzsche
}

Jorge Luiz Viesenteiner

Professor do programa de Pós-Graduação da PUC-Paraná

\section{RESUMO}

O objetivo desse artigo é analisar a hipótese de compreensão do homem enquanto somatória unitária de vivências (Erlebnisse). Como 'animal ainda não determinado', o homem pode receber inúmeras formas, sem quaisquer determinações a priori de caráter conceitual, de modo que sua compreensão pode ser continuamente deslocada e em abertura. O fio condutor dessa análise é a noção de Erlebnis entendida como contra-conceito à razão, i.e., como pathos, bem como caracterizada a partir de três perspectivas: imediatez, significabilidade e a dimensão estética. A tarefa de tornar-se o que se é, portanto, tem de se realizar em meio às vivências em um contínuo exercício de construção de si mesmo.

Palavras-chave: Erlebnis; Homem; tornar-se o que se é.

\begin{abstract}
The aim of this paper is to analyze the possibility of understanding the human as unitary summing of experiences (Erlebnisse). As "animal not yet determined", man can receive numerous forms, without any a priori and conceptual determinations, so that your understanding can be continuously shifted as well as remain always opened. The guiding concept of this analysis is the notion Erlebnis understood as a counter-concept to the reason, i.e., as pathos, and characterized from three different perspectives: immediacy, meaningfulness and aesthetic dimension. The task of 'becoming what one is', therefore, must take place through the Erlebnisse in a continuous exercise over itself.
\end{abstract}

Key-words: Erlebnis; Man; to become who one is. 


\section{Introdução}

$\mathrm{N}$ ietzsche se refere ao homem moderno, especialmente no horizonte de sua corrosiva crítica operada em Além do bem e do mal, como "animal de rebanho" (cf. p. ex., ABM 203)1, mas também o exprime positivamente como "o animal ainda não determinado" (ABM 62). Isso significa que o homem, por um lado, embora não sobreviva à indeterminação "ainda não determinado" -, também não pode, por outro lado, identificar-se em definitivo com nenhuma forma que impõe a si mesmo. ${ }^{2}$ Nesse caso, homem é um conceito que nunca pode ser efetivamente conceitualizado, sobretudo definido a-historicamente, mas tem de ser compreendido a partir de um horizonte que pode continuamente ser deslocado, recebendo um sentido de plena abertura, mas também, simultaneamente, integrador de várias formas em si mesmo.

A preocupação com um horizonte possível de compreensão do homem sempre esteve presente, por exemplo, na noção de Bildung (formação/cultura), termo alemão estreitamente vinculado à Paideia: “A palavra alemã Bildung [...] é a que designa do modo mais intuitivo a essência da educação no sentido grego e platônico." (JAEGER, 1995, p. 13)³. Formar um homem pressupõe, nesse

${ }^{1}$ Utilizaremos as seguintes referências para os textos de Nietzsche. Para os apontamentos póstumos, indicaremos o ano do apontamento, o número do apontamento, seguido da referência na KSA (Kritische Studienausgabe - a edição crítica das obras completas de Nietzsche) com o número do volume e página (p.ex.: Nachlass 1888, 9[1], KSA 8, p. 23). Para as cartas empregamos a abreviação KSB (Sämtliche Briefe) seguida do volume e o número da carta (KSB 8, carta n. 1104). Para as referências de obras enviadas à publicação de Nietzsche, seguese a abreviação do livro (p.ex., NT para $O$ nascimento da tragédia; Cons.Ext. II, HL para Considerações extemporâneas II, Da utilidade e desvantagem da história para a vida; $\mathrm{HH}$ para Humano, demasiado humano; A para Aurora; GC para A Gaia Ciência; Za para Assim falou Zaratustra; ABM para Além do bem e do mal; CW para O caso Wagner; CI, para Crepúsculo dos Ídolos; EH para Ecce homo e AC para Anticristo) e número do aforismo (p.ex., A 33; GC 343, EH, Crepúsculo dos Ídolos 1; CI, Considerações de um extemporâneo 44, etc.). As traduções dos apontamentos póstumos e da bibliografia em alemão são de minha autoria. Privilegiamos as traduções de Paulo César de Souza ao citarmos as obras publicadas em português

${ }^{2}$ Sobre a análise da fórmula do homem como 'animal ainda não determinado', cf. TONGEREN (2012, p. 113-116).

${ }^{3}$ Cf. também WEBER (2011). 
caso, configurá-lo a partir de um horizonte de compreensibilidade do humano, cujo horizonte será aquele através do qual a formação deveria se orientar. Além disso, esse horizonte de formação também tem de estar de tal modo em abertura, a fim de ser igualmente possível seu contínuo deslocamento. Considerar o homem como o 'animal ainda não determinado' significa justamente assumir um horizonte de formação, no qual tanto o homem quanto sua formação mesma podem sempre ser superados, ou ainda, que ambos são assumidos na perspectiva de transição e deslocamento, tal como anunciado por Zaratustra: "O homem é uma corda estendida entre o animal e o super-homem [...]. O que há de grande, no homem, é ser ponte, e não meta: o que pode amarse, no homem, é ser uma transição e um ocaso.” (Za, Prólogo 4) 'Transição' e ‘ocaso' significam, respectivamente, contínuo deslocamento de sentido bem como capacidade de pôr fim a uma determinada forma, a fim de que o novo apareça! Querer ser transição é querer ser o 'animal ainda não determinado', e querer "o seu próprio ocaso" (Za, Prólogo 4) é assumir a perspectiva de pôr fím a uma forma, a fim de construir ou permitir que outra possa surgir em seu lugar.

A partir da perspectiva do 'animal ainda não determinado', abre-se então a hipótese de que o homem tem por tarefa o contínuo exercício de construir ou formar a si mesmo, ou seja, a tarefa de 'tornar-se o que se é' que se desdobra única e exclusivamente na própria vida e em meio às vivências, termo alemão registrado como Erlebnis (vivência). Acrescente-se que não se trata de um 'tornar-se' oriundo de um saber prévio sobre si mesmo, mas antes de um desdobramento fenomenológico de engajamento homem/mundo, cujo 'tornar-se o que se é' é a tarefa que o homem tem de assumir a partir das suas Erlebnisse (vivências). Em sua autogenealogia filosófica Ecce homo, Nietzsche escreve: "Que alguém se torne o que é pressupõe que não suspeite sequer remotamente o que é." (EH, Por que sou tão inteligente 9) Nesse caso, Nietzsche desloca o eixo socrático do conhece-te a ti mesmo, cujo saber se desdobraria no mundo a partir de uma práxis, para situá-lo de forma pathetica de exclusiva construção de si no mundo. A frase que empresta o subtítulo ao livro Ecce homo, vale dizer, 'como alguém se torna o que é', é uma inspiração das Odes Píticas de 
Píndaro, notadamente a segunda das "Odes" dirigidas a Hieron que reza " $\Gamma$ ćvol'

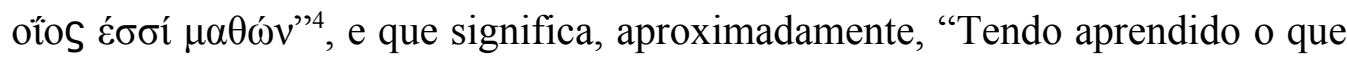
você é, torna-te tal como você é"; ou ainda, "Sê fiel a ti mesmo agora que aprendestes que espécie de homem te apetece", ou simplesmente "Seja o que você conhece que você é". ${ }^{5}$ Curiosamente, Nietzsche retira do subtítulo do seu livro a palavra " $\mu \alpha \theta \omega ́ v "$ (mathon), precisamente aquela que alude à medida ou ao conhecimento/aprendizado de si mesmo. Ao invés então de primeiramente aprender algo sobre si, para então se tornar aquilo que aprendeu sobre si mesmo, Nietzsche desloca o eixo teórico do 'tornar-se o que se é', dizendo: “Que alguém se torne o que é pressupõe que não suspeite sequer remotamente o que é." (EH, Por que sou tão inteligente 9). Não há um aprender ou conhecer a si mesmo anterior ao próprio tornar-se, mas apenas um tornar-se em meio às próprias vivências e suas inseguranças, num engajamento de imediatez entre homem e mundo, bem como significabilidade do vivenciado para o próprio homem.

A partir desse pano de fundo teórico, arriscamos aqui uma hipótese sobre o homem, qual seja, entendê-lo como uma somatória unitária de vivências. Se o homem tem por tarefa construir a si mesmo, assim ele o faz aquém de quaisquer intencionalidades teóricas, bem como fundamentalmente por meio das suas vivências. Negativamente definida, por um lado, vivência (Erlebnis) é um contra-conceito da razão, ou seja, pathos, e, enquanto tal, trata-se de um conceito que não pode ser compreendido tal como se entende um conceito, ou seja, de forma unívoca e universal. Nesse caso, vivência é uma noção que se desvia da compreensibilidade conceitual, de modo que tão logo ela seja conceitualmente definida, deixa de ser pathos e se torna conceito tradicional. Por outro lado, a ocorrência da palavra vivência aparece no vocabulário alemão pela primeira vez a partir da primeira metade do século XIX, e ganha estatuto

${ }^{4}$ Pítica 72, genoi' hoios essi mathon. Sobre o tema cf. NEHAMAS (2002), especialmente a nota 2 do capítulo seis, intitulado "como se chega a ser o que se é".

${ }^{5}$ Sobre essa discussão, cf. BABICH (2003, p. 31): "Embora o verso de Píndaro seja de difícil tradução, há uma falta de padrão e padronização nas traduções". As traduções são: "Become such as you are, having learned what that is"; "Be true to thyself now that thou hast learnt what manner of man thou art"; "Be what you know you are." 
filosófico só em meados do mesmo século (CRAMER, 1972, p. 702). ${ }^{6}$ Substantivado a partir do verbo erleben, Erlebnis significa "estar ainda presente na vida quando algo acontece" (idem, p. 703), ou seja, nunca estamos absolutamente conscientes daquilo que vivenciamos, enquanto efetivamente vivenciamos, donde se segue a diferença entre as palavras Erlebnis (vivência) e Erfahrung (experiência). ${ }^{7}$ Além disso, o que caracteriza a uma vivência é precisamente sua dimensão de imediatez na relação homem/mundo, bem como de significabilidade daquilo que é vivenciado. 'Estar ainda presente na vida quando algo acontece' implica na estreita imediatez, e, além disso, algo que foi vivenciado (efetivamente sentido) por alguém precisa alterar o caráter global da existência, indicando sua dimensão de significabilidade. Acrescente-se, por fim, a noção de incomensurabilidade do conteúdo da vivência, de modo que não se trata de fazer indicativos sobre o quê se deve vivenciar, ou vivenciar como um "desejo de vivência" (CI, Incursões de um extemporâneo 7), isto é,

${ }^{6}$ A prova mais antiga do uso da palavra parece ser uma carta de Hegel de 1827 (Briefe, Ed. Hoffmeister, III 179), na qual ele escreve a palavra Erlebnis - como gênero feminino ainda -, referindo-se a um acontecimento pessoal: "toda minha vivência". A filosofia do século XVIII ainda não estabelece uma diferença entre " "vida' e 'experiência' ", "e para Kant e os kantianos, Schelling e Hegel, a palavra não indica nenhuma função conceitual" (CRAMER, 1972, p. 703).

${ }^{7}$ A diferença entre Erlebnis e Erfahrung (experiência) pode ser observada com base na primeira elaboração do verbete Erlebnis em um dicionário da língua alemã - "Encyklopädische Lexikon in bezug auf die neuste Literatur und Geschichte der Philosophie" -, organizado por Wilhelm Traugott Krug em 1838. O verbete reza: "Erlebnis significa tudo o que propriamente se vivenciou (sentiu, presenciou, pensou, quis, fez ou permitiu). Tais vivências, pois, são as condições da própria experiência, se através daí se entende extrair certos resultados" (CRAMER, 1972, p. 705). Erlebnis consiste nas condições para toda Erfahrung, na medida em que esta última é constituída por uma mediação especificamente lógica. Enquanto Erlebnis tem seu estatuto determinado pelo caráter imediato naquilo que ocorre, carregando pois seu cortejo de sentimentos, Erfahrung implica em constituição lógica através desse cortejo de Erlebnisse: "Erlebnisse não são as estruturas que constituem a própria Erfahrung como tal, mas apenas as condições. Erfahrung só é constituída através das mediações especificamente lógicas, e que na verdade se relacionam sem exceção com as Erlebnisse, mas ela não tem o caráter da imediatez que tem a Erlebnis. [...] Erlebnisse não são condições subjetivas da Erfahrung, mas representam verdadeiramente a realidade daquilo que se chama Erfahrung. O autor do verbete Erlebnis, no doravante $2^{\circ}$ volume do Nietzsches Wörterbuch, também faz uma diferença entre Erlebnis e Erfahrung. Com base em expressões alemãs - que a meu ver encontram sim correspondências no português -, Erfahrung tem a característica de uma doutrina cujo significado é "prático-moral", ou seja, só depois que se tem a Erfahrung mesma é possível extrair uma avaliação do que se experimentou: “'Agora você experimentou por contra própria!'. Essa Erfahrung tem um significado prático-moral, ela é uma doutrina”. (VISSER, 2005, p. 25). Erlebnis, ao contrário, tem um "significado estético-individual". Quando se trata de vivência, a expressão alemã ocorre quando se pergunta: "Como te agradou essa vivência?", e não "agora você mesmo vivenciou". Em suma, Erlebnis tem significado estético-individual, enquanto Erfahrung prático-moral. 
como um planejar intencionalmente algo a ser vivenciado. Portanto, uma terceira característica da vivência, em virtude da sua incomensurabilidade, é sua dimensão estética (cf. VIESENTEINER, 2009). Em suma, Erlebnis pode ser caracterizada a partir do horizonte de imediatez, significabilidade e estético, de modo que se revela sobretudo como um contra-conceito à razão e, nesse caso, como pathos.

Na medida em que a Bildung pressupõe orientar-se por meio de um horizonte possível de compreensão do homem, entendê-lo então como somatória unitária de vivências pode se colocar como hipótese a ser discutida, hipótese essa sempre aberta e sem quaisquer perspectivas fundantes, tal como veremos a seguir de forma mais detalhada.

\section{Nietzsche e o homem como somatória de vivências}

O homem pode "criar várias formas" através do exercício do cultivo de si, desde que tenha conquistado a si mesmo. ${ }^{8}$ A princípio, a fórmula 'tornar-se o que se é' não pode sequer entrever uma concepção de homem, na medida em que este é sempre um horizonte aberto e indeterminado e, além disso, se a tarefa de 'tornar-se o que se é' é assumida como um destino, aquilo que alguém se tornou também não pode ser querido de outro modo, nem ser o desdobramento intencional de um "Si". O próprio Nietzsche deixou uma imensa lacuna na concepção, por exemplo, de além-do-homem (Übermensch), pois nunca o explicou sistematicamente, apesar do termo ocorrer inúmeras vezes. Tal como o eterno retorno, a concepção de além-do-homem é frequentemente apenas evocada, mas não explicada. Porém, não está em questão definir o conceito de além-do-homem, pois o próprio Nietzsche também nem sequer poderia ter explicado sistematicamente o conceito, a não ser mesmo de maneira evocativa e apenas como "signo". Antes disso, trata-se de traçar as linhas gerais que correm

${ }^{8}$ A 437: "Quem realmente possui a si mesmo, isto é, conquistou definitivamente a si, vê doravante como privilégio próprio castigar-se, perdoar-se, compadecer-se de si mesmo: ele não precisa concedê-lo a ninguém, mas pode livremente passá-lo às mãos de outro, de um amigo, por exemplo - mas sabe que assim confere um direito, e que direitos podem ser conferidos apenas desde que se possua poder". 
na esteira da noção de cultivo de si através das Erlebnisse, cujo pressuposto mais básico, todavia, é que o homem efetivamente atravesse por Erlebnisse capazes de transformá-lo, tal como, por exemplo, a incorporação do eterno retorno. A vida resulta empobrecida para aquele que é incapaz de vivências.

Não se trata também de atravessar uma única vivência, mas uma somatória de "destinos e convulsões" ou ter "um punhado de saber e uma sacola plena de experiências" (A 449), na medida em que a jardinagem de si mesmo pressupõe estilizar o caráter ininterruptamente: não se perca de vista que quem permanece o mesmo, é porque dá preferência à sólida reputação (GC 296) e exige de si e dos outros hábitos duradouros (GC 295). Neste caso, é preciso considerar o homem como uma somatória unitária de vivências, produto das suas mais variadas peregrinações pela seara do romantismo, pessimismo, cristianismo, etc., de tal modo que ele tenha cada uma dessas vivências ou "tipos de vida" escaldada e curtida dentro de si mesmo, formando uma espécie de "depósito de fantasias" (ABM 223). Segundo Nietzsche, o homem precisa ser de tal modo sintético e integrador, que a capacidade para "sentir o conjunto da história humana como sua própria história" caracterizaria a sua "futura humanidade" (GC 337). Um detalhe fundamental nessa concepção é que ela traz consigo a gratidão e a afirmação de todo 'foi assim', o reconhecimento do "necessário" na fórmula que diz: "o tornar-se arrasta atrás de si o haver sido" (A 49) e, portanto, a confissão de um agradecido pelas mais variadas vivências que atravessou, sem que tenha outra coisa a dizer a não ser: "eu mesmo não quero tornar-me diferente" (EH, Por que sou tão inteligente 9). Se 'tornar-se o que se é' é assumido como um destino, o resultado final dessa jardinagem sobre si precisa, igualmente, ser afirmado como necessário.

$\mathrm{Na}$ primavera/outono de 1881, Nietzsche escreve um apontamento póstumo intitulado "Para o "esboço de uma nova forma de viver"” em quatro livros, sendo que o último contém: "a transformação ininterrupta — você deve atravessar por vários indivíduos em um breve espaço de tempo." (Nachlass 
primavera/outono 1881, 11[197], KSA 9, p. 519)9 O esboço de uma "nova forma de viver" foi escrito à mesma época e lugar do primeiro plano sobre o eterno retorno e, de fato, essa concepção não ocorre antes de agosto de $1881 .{ }^{10}$ Trata-se de uma "nova forma de viver" que nasce estreitamente vinculada à seara da "necessidade" ou do amor ao destino de todas as coisas, e, sobretudo, da "necessidade" em relação àquilo mesmo que o indivíduo vivencia, que nunca pode ser única e nem permanente. Também interessante é que o apontamento coincide com o nascimento do personagem Zaratustra, cujo advento ocorre associado tanto ao eterno retorno quanto às "indicações para uma nova vida", tal como Nietzsche escreve no texto imediatamente anterior, intitulado "Meiodia e eternidade": "Zaratustra nasceu no lago de Urmi e, aos trinta anos de idade, abandonou sua terra natal e foi à província de Ária e por dez anos viveu de sua solidão na montanha de Zend-Avesta." (Nachlass primavera/outono 1881, 11[195], KSA 9, p. 519) Essas anotações são da mesma época da finalização do livro IV d'A Gaia Ciência, livro esse que representa o melhor experimento de Nietzsche em relação ao cultivo do homem.

Do apontamento mencionado é importante ressaltar duas questões: por um lado, a informação que não basta uma vivência ou atravessar por apenas um tipo humano. Ao invés disso, trata-se da capacidade de "afirmar vossas condições de vida e casualidades, para então se transformar em outra: não basta ser Um homem [...], mas a partir de um se tornar outro e vivenciar uma série de seres!” (Nachlass primavera/outono 1881, 11[304], KSA 9, p. 558) ${ }^{11}$ O mesmo também vale para a vivência de "uma série de ideais" (Nachlass primavera/outono $1881,11[258]$, KSA 9, p. 539) ${ }^{12}$ no sentido de alguém que

${ }^{9}$ Este apontamento póstumo foi escrito em 26 de agosto de 1881, em Sils-Maria. Cf. também 11[276], KSA 9, p. 547: “A transformação do homem precisa de milênios para a formação de um tipo, ou então gerações: finalmente, ao longo da vida o homem atravessa por vários indivíduos."

${ }^{10}$ Nachlass primavera/outono $1881,11[141]$, KSA 9, p. 494. O primeiro plano para o "eterno retorno" é do início de agosto de 1881, também em Sils-Maria.

11 Cf. também Nachlass outono 1881, 13[3], KSA 9, p. 618 registrado no grupo de apontamentos sobre a leitura que Nietzsche fez de Emerson, que por sua vez, exerce influência direta e decisiva sobre Nietzsche.

${ }^{12}$ Sobre o tema, confira VISSER (1999). O autor analisa o homem, dentre outras coisas, a partir do aforismo 113 d'A Gaia Ciência e se refere também à exigência de possuir inúmeros "seres" dentro de si, pois o aforismo se refere à unidade entre "forças artísticas e a sabedoria prática", 
veste outras tantas fantasias e as escalda dentro de si. Ora, essa concepção só poderia, de fato, surgir à época do livro IV d'A Gaia Ciência, pois ali estão lançadas as premissas do cultivo do homem sob a rubrica da "necessidade" em se “dar estilo ao caráter” (GC 290). A vivência de vários ideais ou diferentes "saúdes" confere ao homem, "por experiência", "olhos" característicos da consideração estética e "mãos" (GC 249) ${ }^{13}$ típicas do escultor de si mesmo. A travessia por vários "seres" pressupõe, pois, utilizar cada um dos anteriores como uma "função". Se não basta ser "um" homem, diz Nietzsche, "então deves ser alguém que tenha caminhado por muitos indivíduos e que este último utilize todos os anteriores como função." (Nachlass outono 1881, 13[5], KSA 9, p. 619) ${ }^{14}$ Porém, compreender essa sentença pressupõe a analisarmos à luz do movimento de Erlebnis. Só quem foi pessimista ou romântico até a medula e escaldou essas fantasias ou ideais dentro de si pode se desprender e, de quando em quando, voltar a vestir tais ideais com toda "boa consciência". É importante lembrar, por fim, que a vivência desses ideais ou seres nunca se dá como um "desejo de vivência", como Nietzsche registra no Crepúsculo dos Ídolos (CI, Incursões de um extemporâneo 7); ao contrário, segundo Nietzsche, se

bem como "o pensamento científico" reunidos em um "sistema orgânico mais elevado" (GC 113). Assim, "Pensamento científico é para nós a atividade do erudito; consideramos forças artísticas como dom do artista; e falamos de sabedoria prática preferencialmente ao legislador". (p. 109). E relacionando ao além-do-homem escreve: "A visão de Nietzsche do além-dohomem se referiu, pois, a uma essência que se comporta de tal como em relação ao mundo e a si mesmo, que não apenas a vontade de verdade se tornou plenamente instinto, mas também a vontade de beleza e a vontade de justiça. Porém, o decisivo ai é que estes instintos se transformaram uns nos outros entre si" (p. 111).

${ }^{13}$ No aforismo Nietzsche se refere ao "suspiro do homem do conhecimento". A alusão aos "olhos" e "mãos" já havia sido registrada no aforismo intitulado "Nossa derradeira gratidão para com a arte" (GC 107), onde há a mais explícita alusão de que só como "fenômeno estético a existência ainda nos é suportável" e, além disso, a "boa consciência, para poder fazer de nós mesmos um tal fenômeno", pois através da "arte nos são dados olhos e mãos". Essa habilidade, ou melhor, a "boa consciência" para poder considerar-se esteticamente, ocorre somente "mediante muitos indivíduos", como Nietzsche escreve no aforismo citado, ou "várias pessoas", como ocorre no apontamento ligado à ele, 11[65], KSA 9.

${ }^{14}$ Cf. também KAULBACH (1980, p. 75). Na p. 126, o autor interpreta a questão do "amor fati como amor à eternidade", que por sua vez, possuiria precisamente a unidade de tudo em si: "A fisionomia da 'eternidade' traz a ampla unidade dionisíaca na multiplicidade de formas de vida possíveis. [...] Cada momento na imagem desse processo circular mostra não apenas à natureza, mas também à história humana e suas interpretações de mundo, o correto 'point de vue', a 'abundância e poder transbordante' que se localiza na força de reunião de todas as possíveis concepções de vida e mundo em geral.” (cf. também idem, p. 174). 
"possuímos em nós o esboço de várias pessoas" e que "a cada instante de nossa vida há ainda muitas possibilidades", não está em nossas mãos controlar esses instantes, mas antes é "o acaso que sempre brinca junto!" (Nachlass primavera 1884, 25[120], KSA 11, p. 45)

Por outro lado, ressaltamos que se trata de um processo denominado como "transformação ininterrupta". Trata-se do caráter de "abertura"15 que permeia tanto o processo de travessia pelas vivências quanto a compreensão do próprio homem. Essa abertura deve ser compreendida no rigoroso sentido de que cada época, ideal ou tremor pelos quais o homem atravessa, apesar de parecerem “que ele é o único estado então possível e razoável para nós”, nunca se configura em "ethos" definitivo, mas sim apenas o "pathos" (GC 317) que jamais é instrumentalizado pela razão sob a forma de intencionalidade, ou conceitualmente sistematizado de maneira imediata. Na medida em que o homem é "sempre outro" (GC 307), a tarefa de definir o homem passa a ser uma luta inglória, a não ser que o faça astutamente de maneira negativa. Se o ponto de partida de análise do homem como somatória de vivências é pathos, não cabe qualquer intencionalidade no processo de se 'tornar o que é', mas só a afirmação do necessário em todo acontecer, inclusive em relação àquilo que ele mesmo se tornou, sem que o quisesse de outra maneira (cf. VIESENTEINER, 2010). Cada travessia por um ideal, um "ser", uma Erlebnis, enfim, não se instrumentaliza como ethos, a não ser sob a forma de exigência por algo incondicional a qualquer custo. Segundo Nietzsche, essa é uma tendência típica daquele ao qual falta o pathos da distância, ou seja, uma "distância" tal que é conquistada exclusivamente por aquele que está suficientemente aprofundado ou escaldado, sem que precise falar a "linguagem do fanatismo" (Nachlass primavera $1880,3[1]$, KSA 9, p. 47) ${ }^{16}$

Em Além do bem e do mal Nietzsche classificou essa ausência de pathos, como a veneração que a alma jovem e fanática faz "sem a arte da nuance, que

${ }^{15}$ Nachlass outono 1880, 6[147], KSA 9, p. 234, especialmente onde Nietzsche escreve sobre a "liberdade artística" de "podermos, a partir de todas as nossas forças, criar várias formas, ou também a ausência de qualquer forma."

${ }^{16}$ Sobre essa questão, cf. também BRUSOTTI (1994). 
constitui nossa melhor aquisição na vida." (ABM 31) ${ }^{17}$ A pobreza na arte de nuances ${ }^{18}$ implica na incondicionalização de todas as coisas, ou seja, "o pior dos gostos, o gosto pelo incondicional", e acaba-se por "atacar de tal modo com Sins e Nãos as pessoas e as coisas: [...] a ira e a reverência, que são próprias da juventude, parecem não descansar enquanto não tenham falseado as pessoas e coisas de maneira tal que possam nelas se desafogar." Passados alguns anos, a sensação de ter “chegado" em algum lugar, graças à virtude da probidade ${ }^{19}$, é tão intensa quanto a intensidade das desilusões sentida depois que, finalmente, ela "se volta desconfiada contra si mesma". Ainda de forma inocente, a alma se martiriza tentando compreender como pode ter se dedicado a uma "cegueira voluntária!" naqueles anos de pobreza de nuances, numa suposta sensação de que, agora, teria finalmente atingido o ethos da vida, o ponto definitivo: a probidade, aparentemente, foi quase escaldada e abandonada por completo. Neste ponto, o espírito toma "partido, toma[mos] partido por princípio, contra a ‘juventude"”. Porém, acrescenta Nietzsche ao final, "um decênio depois: e compreendemos que tudo isso também - era ainda juventude!"20

Por mais que o homem se esforce em intencionalizar um pathos, sempre será desarmado ao se deparar com um contexto em que se impõe

\footnotetext{
${ }^{17}$ Importante lembrar que um conceito para nuance é também pathos. Cf. STEGMAIER (1992, p. 171).

${ }^{18}$ Cf. A 495, em que Nietzsche se refere também à "infantilidade" da alma fanática em tornar os "mestres e orientadores" incondicionais. E arremata: "Por essa infantilidade temos de pagar caro depois: temos de expiar nossos mestres em nós".

${ }^{19}$ No aforismo 31 Nietzsche se refere ao "gosto pelo incondicional" como contra-conceito de alguém que ainda não aprendeu "a pôr alguma arte nos sentimentos" e, sobretudo que não arriscam na experiência do "artificial: como fazem os veros artistas da vida". Ao se referir às noções de artificial ou arte como contra conceito do incondicional, o que está na base dessa consideração é precisamente a probidade. Ora, n'A Gaia Ciência 107, a arte foi evocada como a "força contrária" que impede no homem a radicalização da "probidade", cujo ponto de culminância seria a "náusea e o suicídio". É preciso lembrar que mesmo a probidade deveria também ser escaldada pelo espírito, como mais uma vivência que alteraria suas condições de vida. A sedução da probidade ou da incondicionalidade na probidade culmina na limitação e estupidez do homem: "Nossa probidade, nós, espíritos livres - cuidemos para que não se torne nossa vaidade, nosso adereço e arabesco, nosso limite, nossa estupidez!” (ABM 227. Tradução modificada). A arte, portanto, ou a experiência do "artificial", é a força contrária que precisa ser conquistada por aquele que ainda se encontra na seara do fanatismo. Sobre o tema, cf. TONGEREN (2012).

${ }^{20}$ ABM 31. Este texto foi originalmente escrito como primeira parte para "uma nova consideração extemporânea" composta por 9 capítulos, especialmente para repensar Wagner, em agosto-setembro de 1885, 41[2]1, KSA 11, p. 669ss.
} 
ininterruptamente como juventude, sem que ele chegue em qualquer lugar definitivo. Como mais uma característica de pathos, o destino é o meio através do qual o homem assume a tarefa de se tornar o que é, que parte do ponto em que ele "não suspeite sequer remotamente o que é" (EH, Porque sou tão inteligente 9) e, além disso, alcança um ponto igualmente não-racionalizável de se saber, previamente, o que se tornará. Nesse processo não há uma formulação conceitual através da intencionalidade. Mesmo que o homem se apresse em convencer-se do "ethos" que vive como o "único possível e razoável" para ele, cada Erlebnis seguinte o encaminha a outro pathos. Ora, o pathos mesmo da vida o desarma ininterruptamente e se impõe diante dele como a necessidade de reconhecer que, naquela época ou ideal, era justamente apenas "pathos e paixão" (GC 317), e nada definitivo. "Outrar-se" na mais rigorosa abertura é o que lhe apetece, mas sem saber em que vai se tornar.

Cada travessia por "seres", ideais, Erlebnisse, enfim, precisa aprofundar de tal modo o espírito até convertê-lo no mais sintético e somador de todos os homens. Não se trata, pois, de mero turismo de burguês ocioso, mas da unidade de vivência em si, como "soma": "Vivenciar muitas coisas: co-vivenciar muitos passados; vivenciar, como unidade, muitas das vivências próprias ou estranhas: isso faz os homens mais superiores; eu os denomino 'soma'." (Nachlass novembro 1882/fevereiro 1883, 5[1]30, KSA 10, p. 191) Apesar de surgir apenas a partir de 1881, essa concepção é reafirmada até os últimos escritos, por exemplo, em Ecce homo. Ali Nietzsche se refere às doenças pelas quais vivenciou, escrevendo, por um lado, que foi através delas que deixou "de ser um pessimista" e, por outro lado, conseguiu fazer "vingar" uma vida: "Um homem que vingou faz bem a nossos sentidos [...]. De tudo o que vê, ouve e vivencia forma instintivamente sua soma." (EH, Por que sou tão sábio 2$)^{21}$ Enfatize-se bem que a vivência unitária do homem até formar "sua soma" não ocorre através da instrumentalização de um processo, sob o signo da intencionalidade. Ao contrário, o "homem sintético, somador, justificador" ocorre no âmbito dos afetos e só como "símbolo" pode ser mencionado e,

\footnotetext{
${ }^{21}$ Tradução modificada. Cf. ainda Nachlass primavera 1888, 15[39], KSA 13.
} 
acrescente-se, o "símbolo" para este homem somador é precisamente a "palavra além-do-homem." (Nachlass outono 1887, 10[17], KSA 12, p. 462s.).

Apenas o homem suficientemente escaldado pode ser "somador" ou ansiar por "totalidade" (CI, Incursões de um extemporâneo 49) como o clássico exemplo de Goethe que, apesar de ser "o mais abrangente" não abriga em si as vivências caoticamente ordenadas. (cf. Nachlass outono 1887, 9[179], KSA 12, p. $443 \mathrm{~s}$.)

O homem concebido por Goethe era um homem forte, de cultura elevada, hábil em todas as atividades corporais, que tem para si as rédeas na mão, que sente reverência diante de si mesmo ${ }^{[1]} ;[\ldots]$ o homem da tolerância, não por debilidade, mas por fortaleza, porque sabe empregar em proveito próprio aquilo que faria perecer a natureza mediana ${ }^{[2]} ;[\ldots]$ Com um fatalismo alegre e confiado esse espírito que se tornou livre está imerso em tudo - [...] esse espírito já não nega mais $^{[3]}[\ldots]$; Mas tal crença é a mais alta de todas as crenças possíveis: eu a batizei com o nome de Dionísio $^{[4]}$. (CI, Incursões de um extemporâneo 49)

Esse trecho contém vários dos elementos teóricos que nos interessam. Por isso, a concepção do homem como somatória unitária de vivências é bem caracterizada por essa relação com Goethe. Vejamos: [1] A "reverência diante de si mesmo" é a característica do homem que alcançou o saudável "sentimento de distância" (EH, O caso Wagner 4) dentro de si que, no fundo, Nietzsche denominou a partir de Além do bem e do mal de "pathos da distância" (ABM 257). Essa característica da "alma nobre" (ABM 287) não é um presente, mas sim, algo que primeiro pressupõe uma travessia e só pode entrar em consideração como conquista de um direito. Trata-se do "grande pathos", aquele em que o homem tem "reverência diante de si mesmo" (Nachlass maio/julho 1885, 35[24], KSA 11, p. 518), do pathos da distância, cujo excesso perdulário de vida cria a partir da abundância (cf. GC 370). Ora, Goethe possui no corpo a marca distintiva de toda "auto-superação", que é um "meio de ter e exigir reverência diante de si" (Nachlass final de 1886/primavera 1887, 7[5], 
KSA 12, p. 271). [2] Como "homem da tolerância", Goethe só o poderia ser não por debilidade, mas por fortaleza, tal como a fórmula dos gregos que "eram superficiais - por profundidade!" (GC, Prefácio 4) ${ }^{22}$ Só aquele que é suficientemente forte pode travestir-se em fraqueza, sem ter que se apaixonar definitivamente pela própria fraqueza. Poder ser fraco e desfilar sua fraqueza com toda "boa consciência", ou vestir a fantasia da debilidade sem que ela apodreça no corpo, é típico de quem atravessou essa mesma debilidade até a medula, mas que agora pode retirar a dissimulada fantasia quando quiser, visto que ela já está há muito escaldada dentro de si: uma Erlebnis não "melhora”, ela "aprofunda". Ser "tolerante" à maneira de Goethe, portanto, pressupõe o mesmo movimento de Erlebnis, que por sua vez, dá o privilégio de poder ser fraco por "fortaleza". [3] Vivenciando tudo em si como uma unidade, Goethe assume dessa forma um "fatalismo" que, apesar de ter nas costas o "mais pesado dos pesos", é assumido com jovialidade. Lembremos inicialmente que mesmo o caráter de "provisoriedade do homem", na medida em que é empregado para "o ganho das mais elevadas forças" é precisamente "fatalismo: a forma mais extrema do "eterno retorno"” (Nachlass verão/outono 1884, 27[67], KSA 11, p. 291). Como unidade de vivências, o homem também se assume como "ego fatum", que é igualmente o agradecimento ao qual, "olhando para trás", o homem somador dedica tanto ao "destino" - sem querer que tenha sido diferente - quanto a "si mesmo" - num gesto de "reverência" (Nachlass primavera 1884, 25[158], KSA 11, p. 55). Além disso, o espírito não ganha de presente seu desprendimento, ao contrário, tal como Goethe, trata-se de compreender esse processo como um espírito que foi "tornado livre" (EH, Humano, demasiado Humano 1). Ora, é preciso primeiro percorrer a travessia por uma Erlebnis, cujo desprendimento é tanto uma "vitória" sobre si mesmo e sobre o "foi assim", quanto a conquista do pathos da distância criador. Por isso que o espírito "tornado livre" está imerso em tudo: ele vivencia em si todo estranho e próprio como unidade. [4] Um espírito como Goethe contém em si o

\footnotetext{
${ }^{22}$ Só pode amar a superfície aquele que já esteve nas profundezas: "Quem sabe que é profundo, busca clareza, quem deseja parecer profundo para a multidão, procura ser obscuro." (GC 173)
} 
pathos da distância, mas sua negação ou renúncia não vem da abnegação, pois tal espírito "já não nega mais"; essa renúncia vem da abundância que cresce com a travessia pela Erlebnis: o homem somador Nietzsche "batizou" de "Dionísio". Trata-se da mais extrema forma de "totalidade" que "só é explicado [Dionísio - JLV] por um excesso de força" (CI, O que devo aos antigos 4), e que reúne em si a reverência, a "boa consciência" para além de toda culpa, o amor ao destino e o aprofundamento conquistado pela travessia da Erlebnis e, obviamente, o próprio pathos da abundância.

Goethe é apenas um exemplo da consideração do homem como somatória unitária de vivências. Essa concepção, além disso, constitui o que no homem haveria de mais "humano", o que seria o sentimento mais próprio à sua natureza, enfim, sua "futura humanidade":

De fato, esta é uma das cores desse novo sentimento: quem é capaz de sentir o conjunto da história humana como sua própria história sente, numa colossal generalização, toda a mágoa do doente que pensa na saúde, do ancião que lembra o sonho da juventude, do amante a quem roubaram a amada, do mártir cujo ideal foi destruído, do herói após a batalha que nada decidiu e lhe causou ferimentos e a morte do amigo. (GC 337) $)^{23}$

Atingir a sabedoria dessa futura "humanidade" pressupõe o mais intenso sentimento de agradecimento a cada vivência que este homem escaldou dentro de si. Trata-se de reconhecer a imprescindibilidade de primeiro ter sido religioso ou ter rezado no santuário da metafísica, para só depois poder sacrificar no altar do incondicional cada um desses ideais ou vivências, na medida em que ele não mais se apaixona por essa seara, mas olha para além de si e de maneira desprendida:

${ }^{23}$ Cf. também Nachlass início de 1882, 17[4], KSA 9, p. 666: "Eu quero vivenciar toda a história na própria pessoa e apropriar-se de todo poder e domínio, não curvar-me nem diante de reis e nem de qualquer grandeza." Estes apontamentos constam do caderno de enxertos do livro "Ensaios" de Emerson. Frise-se a fonte na qual Nietzsche está bebendo. 
"Não menospreze ter sido religioso. [...] É preciso ter amado a religião e a arte como a mãe e a nutriz - de outro modo não é possível se tornar sábio. Mas é preciso poder olhar além delas, crescer além delas; permanecendo sob o seu encanto não as compreendemos." (HH 292) ${ }^{24}$

Mais uma vez, a Erlebnis é efetivamente o meio de cultivo do homem ${ }^{25}$, pois o "homem filosófico", como diz Nietzsche, "impele todo o vivenciado em um geral" e "cresce" como uma corrente: ele precisa sentir toda a história como “sua história" (Nachlass junho/julho 1885, 36[56], KSA 11, p. 573):

Mas carregar, poder carregar essa enorme soma de mágoas de toda espécie e ainda ser o herói que, no romper do segundo dia de batalha, saúda a aurora e a sua fortuna, como o ser que tem um horizonte de milênios à sua frente e atrás de si [...]: tudo isso acolher em sua alma, as coisas mais antigas e mais novas, perdas, esperanças, conquistas, vitórias da humanidade: tudo isso, afinal, ter numa só alma e reunir num só sentimento. (GC 337)

Sejam mágoas ou conquistas, ideais e todo tipo de incondicionalidades, ou ainda "morais, artigos de fé, gostos artísticos e religiões", o homem cultiva a si de tal modo que ele acaba se revelando um grande "depósito de fantasias", apesar de perceber "que nenhuma delas lhe cai muito bem - está sempre mudando-as." (ABM 223) E é claro que nada poderia assentar, embora ele possa vesti-las ou mudá-las a hora em que bem entender: cada uma dessas fantasias foi suficientemente escaldada ou "experimentada" dentro de si, de

${ }^{24}$ Em um apontamento póstumo do mesmo período, Nachlass final de 1876/verão 1887, 23[160], KSA 8, p. 463, Nietzsche inclui também a metafísica e a história como mais um degrau ao qual consagrar agradecimento: "Eu quero me tornar sábio até os 60 anos. [...] Devese entender a religião e a arte - senão não se pode tornar-se sábio. Até mesmo a metafísica é um degrau sobre o qual devemos já ter estado. Igualmente a história e o relativo." Cf. ainda GC 300 .

${ }^{25}$ SCHANK $(2000$, p. 345$)$ se refere também ao agradecimento à travessia por ideais ou vivências anteriores, na medida em que isso também é uma forma de cultivo promotor da "elevação do homem": "Primeiramente, a moral cristã traz consigo um 'apequenamento' do homem. Porém, logo que essas características tenham sido adquiridas pelo homem em uma nova síntese do homem futuro, então ela contribui para a elevação do homem." Além da religião, segundo o autor também „a forma de pensamento pessimista“ cultiva o homem e contribui à elevação. (p. 368) 
modo que "romântico, ou clássico, cristão, florentino", enfim, nenhuma delas vai se assentar em definitivo.

Tal como Nietzsche escreveu várias vezes, é provável que tal homem se torne incompreensível, ainda que tal incompreensibilidade seja propriamente seu destino. Impossível dizer o que "é" este homem, por conta do seu amor às máscaras bem como ao fato de ser o mais oculto entre todos aqueles que se revelam. Para além de qualquer intencionalidade, mas sim como pathos, 'tornar-se o que se é' parte do não-saber "o que é” sem também saber o que se tornará, apesar de nada poder desprezar daquilo que vivenciou e nem ter querido de outra maneira. Como somatória de vivências, todas as formas são possíveis, mesmo que incompreensíveis. Enfatize-se, porém, que a mais genuína originalidade daquilo que o homem se tornou, assenta-se precisamente nessa incompreensibilidade, ou no destino de não ser compreendido, conforme Nietzsche registrou em sua Gaia Ciência: “Tal é a nossa sina, como disse: nós crescemos até às alturas; e ainda que isto fosse a nossa fatalidade - pois habitamos cada vez mais próximos dos raios! - muito bem, nós não a reverenciamos menos por isso, ela continua a ser o que não desejamos compartilhar nem comunicar, a fatalidade das alturas, a nossa fatalidade..." (GC $371)$.

Aqui colocamos "a verdadeira interrogação", ou seja, que "o destino da alma dê a volta, o ponteiro avance, a tragédia comece" (GC 382). A tragédia "comece"? Mas Zaratustra venceu o espírito de gravidade, o espírito de peso: ele foi capaz de fazer sucumbir a seriedade em proveito do riso, e por isso Nietzsche nos diz: "tenham cautela!", pois ao invés da tragédia, que a "paródia comece, não há dúvida..." (GC, Prefácio 1) Zaratustra representaria, então, a encarnação do riso como leveza conquistada por aquele que compreende a si mesmo de tal modo que pode continuamente deslocar seu próprio sentido. $\mathrm{O}$ caráter de abertura e de indeterminação, ou ainda, de 'animal ainda não determinado', indica as mais variadas possibilidades de formas, de vivências que, ao cabo de uma trajetória aventuresca, alguém tem de senti-las todas como 
uma unidade, e talvez dizer: "Era isso a vida? Pois muito bem! Outra vez!" (Za Da visão e do enigma, p. 165)

\section{Referências}

BABICH, Babette E. Nietzsche's Imperative as a Friend's Encomium: on becoming the one you are, ethics, and blessing. In: Nietzsche-Studien 32(2003), p. 29-58.

BRUSOTTI, M. Verkehrte Welt und Redlichkeit gegen sich: Rückblicke Nietzsches auf seine frühere Wagneranbängerschaft in den Aufzeichnungen 1880-1881. In: Borsche, T.; Gerratana, F. u. Venturelli, A. (Hrsg.): ,Centauren-Geburten’: Wissenschaft, Kunst und Philosophie beim jungen Nietzsche. Berlin/New York, 1994. p. 435-460.

CRAMER, K. "Erleben, Erlebnis". In: RITTER, Joachim (Hrsg.) Historisches Wörterbuch der Philosophie. Band 2: D-F. Basel/Stuttgart: Schwabe \& Co. Verlag, 1972.

JAEGER, W. Paideia: a formação do homem grego. São Paulo: Martins Fontes, 1995.

KAULBACH, F. Nietzsches Idee einer Experimentalphilosophie. Köln, Wien: Böhlau, 1980.

NEHAMAS, A. Nietzsche: la vida como literatura. México: Fondo de Cultura Econômica, 2002.

NIETZSCHE, F. Sämtliche Werke. Kritische Studienausgabe in 15 Bänden. (KSA) Hrsg. Giorgio Colli und Mazzino Montinari. Berlin/New York: DTV \& Walter de Gruyter, 1999.

- Sämtliche Briefe. Kritische Studienausgabe. (KSB) Hrsg. Giorgio Colli und Mazzino Montinari. Berlin/New York: DTV \& Walter de Gruyter, 1986.

. O Nascimento da Tragédia. (Trad. J. Guinsburg). São Paulo: Companhia das Letras, 2003.

- Humano, demasiado bumano. (Trad. Paulo César de Souza). São Paulo: Companhia das Letras, 2000.

- Aurora. (Trad. Paulo César de Souza). São Paulo: Companhia das Letras, 2004.

- A Gaia Ciência. (Trad. Paulo César de Souza). São Paulo: Companhia das Letras, 2001. 
- Além do bem e do mal. (Trad. Paulo César de Souza). São Paulo: Companhia das Letras, 1998.

. O Caso Wagner/ Nietzsche contra Wagner. (Trad. Paulo César de Souza). São Paulo: Companhia das Letras, 1999.

. Crepúsculo dos idolos. (Trad. Paulo César de Souza). São Paulo: Companhia das Letras, 2006.

Ecce homo. Como alguém se torna o que é. (Trad. Paulo César de Souza). São Paulo: Companhia das Letras, 2004.

- O Anticristo/ Ditirambos de Dionísio. (Trad. Paulo César de Souza). São

Paulo: Companhia das Letras, 2007.

SCHANK, G. Rasse“ und „Züchtung" bei Nietzsche. (Monographien und Texte zur

Nietzsche-Forschung). Berlin/New York: de Gruyter, 2000.

STEGMAIER, W. Nietssches Kritik der Vernunft seines Lebens: Zur Deutung von „Der Antichrist“ und „Ecce Homo“. In: Nietzsche-Studien 21 (1992), p. 163-183.

TONGEREN, Paul van. A moral da crítica de Nietzssche à moral. Trad.: Jorge Luiz

Viesenteiner. Curitiba: Champagnat, 2012.

VIESENTEINER, Jorge L. Experimento e vivência: a dimensão da vida como pathos.

Tese de doutorado (Unicamp), 2009.

O problema da intencionalidade na fórmula 'como alguém se torna o que se é' de

Nietzsche. In: Dissertatio 31 (2010), p. 97-117.

VISSER, Gerard. Nietssches Übermensch: die Notwendigkeit einer Neubesinnung auf die

Frage nach dem Menschen. In: Nietzsche-Studien 28 (1999) p. 100-124.

. Erlebnisdruck: Philosophie und Kunst im Bereich eines Übergangs und Untergangs.

Würzburg: Königshausen und Neumann, 2005.

WEBER, J. Formação (Bildung), educação e experimentação em Nieţsche. Londrina:

Eduel, 2011. 